\title{
CULTURAS TRANS-PARENTES: USOS E COSTUMES DE PRATICANTES DA MÍDIA NAS MARGENS
}

\author{
Alexsandro Rodrigues ${ }^{\mathrm{i}}$ \\ Fabio Diaz Camarneiro ii \\ Ana Paula Figueiredo Louzada ${ }^{\text {iii }}$ \\ Pablo Cardozo Rocon ${ }^{\text {iv }}$
}

\begin{abstract}
Resumo: Este texto busca pensar as produções culturais do cotidiano como práticas de significação de sujeitos trans-parentes (praticantes de imagens e sons nas margens), em processos de negociação com modos de (in)visibilidade a partir dos discursos da mídia. Interessa-nos as narrativas midiáticas a respeito do (des)aparecimento desses corpos precários e vulneráveis, mas também alianças possíveis (como pensadas por Judith Butler) a partir dos materiais da mídia. Se, como disse Susan Sontag, as imagens provocam, ao mesmo tempo, efeitos de engajamento e distanciamento, nossa aposta metodológica se faz através de uma interpretação dos efeitos dos acontecimentos que impedem a expansão de gestos travestis nas mídias e nossa aposta política em contar outras histórias sobre esses gestos.
\end{abstract}

Palavras-chave: Mídia; Cultura; Produção; Gestos; Travestis.

\section{TRANS-PARENT CULTURES: MEDIA PRACTITIONERS' COSTUMES AT THE EDGE}

\begin{abstract}
This article debates how cultural practices could be appropriated by trans-parent subjects (as media practitioners) that deal with images and sounds in order to negotiate different new ways of (in)visibility. Our interest lies on how media narratives (un)veil or (dis)closure these bodies and its precarious and vulnerable situations. Also, how new alliances (after Judith Butler) could be forged in these scenarios. Susan Sontag pointed out that images usually provoke, at the same time, engagement, and distancing. Therefore, our methodology is to interpret the effects of events that may stop travesty gestures. And our political goal is to tell other stories about these gestures besides those focused on violence and death.
\end{abstract}

Keywords: Media; Culture; Production; Gestures; Travesty.

Em A cultura no plural, Michel de Certeau esboça algumas definições:

A cultura é uma noite escura em que dormem as revoluções de há pouco, invisíveis, encerradas nas práticas - mas pirilampos, e por vezes grandes pássaros noturnos, atravessam-na; aparecimentos e criações que delineiam a chance de um outro dia. (...) Cada cultura prolifera em suas margens. Produzem-se irrupções, que designamos como criações relativamente a estagnações. Bolhas saltando do pântano, milhares de sóis explodindo e se apagando na superfície da sociedade. No imaginário oficial, elas figuram como exceções ou marginalismos. Uma ideologia de proprietários isola o autor, o criador ou a obra. Na realidade, a criação é uma proliferação 
disseminada. A criação é perecível. Ela germina. Uma festa multiforme infiltra-se por toda parte (...). Ela passa, pois é ato. De fato, é criador o gesto que permite a um grupo inventar-se. Ele mediatiza uma atividade coletiva. Seu traço talvez sobreviva ao grupo, sob a forma de um objeto que a vida deixou cair, pegou, abandonou novamente e reutilizou ainda em práticas posteriores. (CERTEAU, 1995, p. 239, 242 e 243)

Ao pensar no campo da cultura como o conjunto de práticas de significação e de operações produtoras de sentido, Certeau mira nos cotidianos e no que se passa com seus praticantes. Pensa na vida de todos os dias e em seus sujeitos ordinários. Seus argumentos são centrais para compreendermos as ações culturais, bem como o aparecimento de gestos e práticas invisíveis (que entendemos como microbianas) que se dirigem "para o apagamento da propriedade e do nome próprio" (CERTEAU, 1995, p. 17).

Trata-se aqui de praticantes sem nome ou propriedade, em ações culturais que não se capitalizam. Ao golpear tempo e espaço, ao lançar mão das ocasiões e oportunidades abertas no improvável do acontecimento, suas práticas não se prestam a oferecer à macropolítica que faz a gestão da vida, do corpo, das identidades e dos povos - uma revolução programada.

Esses praticantes da vida cotidiana, em seus exercícios de poder, agem na e com a cultura; desenham paisagens como as dunas que se alteram com a força do vento; reciclam gestos a inventar outras coletividades; colocam em cena as forças da multidão e potencializam vidas e subjetividades por vir.

Como não necessitam da bênção ou da aprovação dos mitos de origem e de suas fundações, não reivindicam nomes ou propriedades. São coletividade - multidões, dispersões em si mesmas, indeterminações, diferenciações e passagens. Na mais íntima relação com suas experiências criadoras, encontram-se processos de diferenciação constituídos por suas histórias, narrativas e memórias - pirilampos que não podem ser localizados em árvores genealógicas, tampouco nos livros existentes ou em seus heróis; muito menos numa linha histórica que se utiliza de um marco zero.

Sem reivindicar parentesco ou filiação, esses praticantes da cultura (da vida cotidiana) desconfiam sabendo (e desconfiando sabem) que

A origem da criação é mais antiga do que seus autores, supostos sujeitos, e ultrapassa suas obras, objeto cujo fechamento é fictício. Um indeterminado se articula nessas determinações. Todas as formas de diferenciação remetem cada passagem a uma obra de outrem. Essa obra, mais essencial do que seus suportes ou suas representações, é a cultura. (CERTEAU, 1995, p. 18)

Com Certeau, compreendemos que os processos culturais e os sujeitos (ao mesmo Revista Interinstitucional Artes de Educar. Rio de Janeiro, V. 7, N. 1 - pág. 254-271 janeiro-abril de 2021: "Pedagogias Vitais: Corpo, Desejo e Educação" DOI: 10.12957/riae.2021.54891 
fabricados pela cultura e dela fabricantes) são feitos e efeitos de linguagens e tecnologias tecidas aos sabores da vida por rastros e restos dos acontecimentos que nos antecederam, que produziram gestos e marcaram corpos e subjetividades.

As marcas desse tempo das práticas produziram corpos, gêneros e sexualidades que hoje nos (con)formam, marcam-nos de forma desigual e produzem efeitos de diferenciação na própria cultura e nos processos de subjetivação.

Mesmo tomando as pessoas travestis como motivo das conversas aqui implicadas, este texto não busca as "origens" das travestilidades (AMARAL et al, 2014). Por ser dispersão, processos de diferenciação, gestos que grudam e desgrudam, o que nos interessa são os acontecimentos. Aos modos de uma criança que, no intervalo do coral de uma igreja qualquer, e ao ser questionado sobre o que seria quando crescesse, responde sem pestanejar: "Travesti”. A mãe e as demais fiéis em suspensão, alguém sugere "Pergunta de novo!". "Fulano o que é mesmo que você vai ser quando crescer?" E a criança pausadamente responde: "Tra-ves-ti... Entenderam? Tra, tra, tra, ves-ti!” Não demora para, lá de longe, o pastor decidir: “Esse menino precisa de oração. Oremos!"”

\section{Na calada da noite, os pirilampos põem a cara no sol}

Na calada da noite, as pessoas travestis — pássaros noturnos, forças deslocantes que não se (con)formam com certos discursos de verdade — atravessam as cidades e exigem reconhecimento. As presenças desses pirilampos, forjadas na coragem de aparecer e existir diante das possibilidades que sustentam, lutam a favor da expansão da vida. Mas, para que possa aparecer e existir, são necessárias condições materiais e políticas que garantam nossas presenças na esfera pública. Para Judith Butler,

A questão do reconhecimento é importante porque dizemos acreditar que todos os sujeitos humanos merecem igual reconhecimento, presumimos que todos os sujeitos humanos são igualmente reconhecíveis. Mas e se o campo altamente regulado da aparência não admite todo mundo, demarcando zonas onde se espera que muitos não apareçam ou sejam legalmente proibidos de fazê-lo? (...) Na realidade, a demanda compulsória por aparecer de um modo em vez de outro funciona como uma precondição para aparecer por si só. E isso significa que incorporar a norma ou as normas por meio das quais uma pessoa ganha reconhecimento em detrimento de outras, estreitando o campo do reconhecível. (...) O próprio fato de que posso perguntar quais humanos são reconhecidos como humanos e quais não são significa que existe um campo distinto do humano que permanece irreconhecível, de acordo com as normas dominantes, mas que é obviamente reconhecível dentro do campo 
epistêmico aberto pelas formas contra-hegemônicas de conhecimentos. (BUTLER, 2018, p. 42-43)

O campo altamente regulado da aparência, que Butler afirma não admitir todo mundo, é ainda mais regulado na mídia de massa, em que as zonas demarcadas — páginas da internet, os feeds, as lives, os vídeos... Para as travestilidades, essas zonas permaneceram, por muito tempo e em sua grande maioria, restritas a alguns poucos discursos: o policial, o médico e aquele ligado a certo entretenimento barato.

Os corpos contra-hegemônicos, ao aparecerem na mídia de massa (ou melhor, como condição para aparecerem na mídia de massa), surgem no noticiário policial, como vítimas de violência. Ou em esquetes de saúde, entre a curiosidade e a necessidade de serem medicados (ou medicalizados). Uma inadequação com seus próprios corpos, ainda que possa ser o caso, surge como imposição. Aparecem ligados a questões de saúde mental, em uma falsa demanda de tratamento ou, ainda outra vez, medicação. Ou na curiosidade (em mais de um sentido cirúrgica) sobre corpos modificados, alterados, ressignificados.

Algumas das zonas demarcadas para corpos contra-hegemônicos impõem padrões às vezes tão estreitos que parece menos problemático a travestilidade que surge como motivo do riso alheio. Mas o que esse riso esconde, além de humilhação, é a impossibilidade desses corpos ocuparem outras zonas de visibilidade midiáticas. Esses corpos precisam de saúde. Esses corpos não são apenas vítimas, e mesmo as vítimas não são apenas vítimas. Esses corpos precisam de políticas de saúde (física e mental) adequadas às suas necessidades. Esses corpos, que sabem viver na calda da noite, também precisam da luz do sol. Também desejam a luz do sol.

Assim como os corpos contra-hegemônicos, essas zonas, cada vez mais, vêm à luz: gestos que questionam as normas de uma humanidade universalista e seu respectivo sistema sexo-gênero avançam. Em alianças por vezes fugazes, esses corpos seguem insistindo em produzir microrrevoluções aos modos das ervas daninhas, dos pirilampos e dos pássaros noturnos que atravessam a grande noite da norma do cisheterosistemapatriarcal, e assim oferecem explosões de sóis na superfície do agora.

As subjetividades travestis exigem o direito de aparecer de um modo em vez de outro e de um modo em vez do modo de um outro. Ervas daninhas, pirilampos, pássaros noturnos e dissidentes do sistema sexo-gênero, as pessoas travestis têm, mediante possibilidades e condições forjadas à contragolpe, a capacidade de aparecer, desaparecer e reaparecer. Exterminá-los é uma outra história.

Em gestos grupais, que fazem o brilho das bundas acontecer em microrrevoluções Revista Interinstitucional Artes de Educar. Rio de Janeiro, V. 7, N. 1 - pág. 254-271 janeiro-abril de 2021: "Pedagogias Vitais: Corpo, Desejo e Educação" DOI: 10.12957/riae.2021.54891 
criativas e resistentes, essas subjetividades nos oferecem imagens, narrativas e linguagens que ensinam a suspeitar da cultura monocultural cisheteropatriacal tradicional e de suas convocações e convenções culturais, organizadas por forças desiguais de poder. Esses corpos buscam — às vezes a ferro e paulada — afirmar seus frágeis modos de vida.

O sistema sexo-gênero cisheteropatriacal e suas extensões midiáticas estão recheados de histórias escritas com sangue e de corpos que não foram enlutados. Dessas histórias, precisamos duvidar, nos esquivar e reescrevê-las. A quem estiver disposto, não faltam histórias. Elas povoam nossas memórias. Contar outras histórias é romper as zonas demarcadas do imaginário da mesma maneira como os limites de uma cidade podem ser rompidos, como as fronteiras nacionais podem ser rompidas pelos imigrantes ditos "ilegais". É um gesto revolucionário. Algo miúdo como gesto, mas não sem importância. São como os pirilampos, que precisam da escuridão da noite para aparecer. É na escuridão da noite que pirilampos se mostram. Durante tempos sombrios, vidas em dissidência, em situação de precariedade e vulnerabilidade, só estão permitidos aparecer e ocupar a cidade na escuridão da noite. Mas isso não basta!

Por não se conformarem em brilhar e aparecer somente na escuridão da noite, as subjetividades contra-hegemônicas inventam modos de vidas clorofilados e desejosos da luz do sol. Não por outro motivo, em gestos coletivos, atualizam o bordão de Natasha Martory ${ }^{\mathrm{v}}$, gesto criador, que diz: "põe a cara no sol, mona! põe a cara no sol, querida! aceita gay, é pra poucas a cara no sol, mona! bicha bonita não se esconde, mostra o rosto, a feminilidade". O jornal Extra não entendeu a expressão "mona" e, ao invés disso, sua manchete online dizia: "Conheça

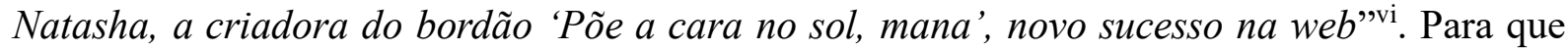
não restem dúvidas sobre a grafia correta do "mona", a conta do Instagram de Natasha afirma: “criadora do bordão: Bota a cara no sol mona. Do Ceará para o mundo"vii.

Natasha Martory não é um ponto de origem (longe disso!), mas um acontecimento. Restos e rastros de tantas outras e outros subjetivam e dão passagem ao acontecimento Natasha Matory. Abrem-se fendas por onde passam essas subjetividades e esses corpos, que assim germinam, brotam. Gestos de grupos e coletivos que se deslocam na calada da noite e com a cara no sol, que fazem funcionar políticas de alianças e atos revolucionários que possam minimizar a vulnerabilidade e criar, no improvável da vida cotidiana, condições que anunciem revoluções microbianas e clorofiladas capazes de afetar as macropolíticas e o que se entende por cultura. 


\section{Contaminações, ressignificações}

Pensamos a revolução enquanto uma ação cultural microbriana, sem autoria e quase invisível, formada por gestos grupais e coletivos inventados por (e que inventam as) pessoas travestis. Gestos surgidos na precariedade e na vulnerabilidade em que são expostas em tempos sombrios. Práticas e exercícios criativos de praticantes que, ao tatearem as bordas do fim do mundo, produzem outros mundos a partir dos restos e cacos do que existe.

Com elas, podemos aprender uma certa forma, um certo modo de ressignificar a produção cultural capturada pelo capital. Aprendemos que os artefatos culturais podem ser questionados e problematizados. Os conteúdos midiáticos não atravessam esses corpos impunemente e, desses encontros, tanto uns quanto os outros saem modificados. O saber dos pirilampos está em usar sua aparente pálida luminosidade para capturar nosso olhar e nossos afetos. Em subverter, mesmo que apenas no nível simbólico, os discursos de opressão. Escapar da lógica de consum(ism)o por frestas - sempre disponíveis a quem saber buscá-las, a quem sabe construí-las. Em regurgitar antropofagicamente os produtos originais em outras coisas e delas tirar proveito.

Para os corpos contra-hegemônicos, a cultura não pode ser mensurada pelo que ela é, mas pelo que ela será. Ao devolverem ao mundo aquilo que recebem do mercado simbólico, eles oferecem luzes imprevistas, antes invisíveis.

Hormônios e anticoncepcionais nos servem como exemplo neste momento!

As pessoas travestis já eram especialistas e mestres nesta arte de inventar corpos e gêneros - muito antes da autorização biomédica das biopolíticas que regulam o que pode um corpo. Elas veem, ouvem, lembram, narram umas às outras, fazem do corpo o primeiro espaço de cultura a ser praticado. E é exatamente pelo corpo que são também capturadas pela cultura visual e pelos artefatos desejantes da cultura. Não estão imunes e, através de diversos artefatos culturais, vendem, descobrem, exploram e consomem corpos, gêneros e desejos.

Nesse sentido, a cultura visual e o artefato cultural (visto como uma máquina de produção de desejo) podem configurar uma das estratégias políticas de governo dos processos de subjetivação, dos corpos, do gênero, da sexualidade, entre outros marcadores que definem vidas que merecem serem vividas.

Não se trata apenas de introduzir novas imagens nos já existentes circuitos de circulação, mas de criar outros circuitos, outros desvios. Corpos desviantes que produzem imagens desviantes para circuitos desviantes. Imagens que entram e saem de outros circuitos mais "convencionais", cuja visibilidade é evidente. E que, nesse processo de contaminação, Revista Interinstitucional Artes de Educar. Rio de Janeiro, V. 7, N. 1 - pág. 254-271 janeiro-abril de 2021: "Pedagogias Vitais: Corpo, Desejo e Educação" DOI: 10.12957/riae.2021.54891 
ressurgem modificadas - e ao mesmo tempo modificam todos os circuitos e todas as estruturas com as quais tiveram contato. É como se em todas as noites daqui para frente, ainda que mergulhadas em tempos escuros, restasse algo da luminosidade fugaz dos pirilampos. Como se uma imagem que ainda não existe já fizesse sentir sua presença.

Torna-se imprescindível - no campo dos estudos culturais, dos estudos feministas, da comunicação e da educação - interrogar a racionalidade beligerante dos enrijecidos circuitos das práticas culturais, para que ela não seja instituída como uma "verdade" nos modos de produção e de consumo de determinadas subjetividades. Estando abertos aos acontecimentos e tateando os espaços de pensamento que estamos percorrendo, recorremos ainda a Certeau (1994), que discute os usos e consumos de sujeitos ordinários diante dos endereçamentos e da produção de desejo.

$\mathrm{Na}$ realidade, diante de uma produção racionalizada, expansionista, centralizada, espetacular e barulhenta, posta se uma produção do tipo totalmente diverso, qualificada como consumo, que tem como característica suas astúcias, seu esfarelamento em conformidade com as ocasiões, suas piratarias, sua clandestinidade, pois ela quase não se faz notar por produtos próprios (onde teria seu lugar?) mas por uma arte de utilizar aqueles que lhe são impostos. (CERTEAU, 1994, p. 94)

Aos modos de Certeau, o consumo nunca é passivo. Nem exercício de poder verticalizado, que age sobre massas amorfas, incapazes de re-agir e de re-utilizar a cultura conforme as inúmeras possibilidades desses encontros.

Nos usos e consumos, nas relações de (des)aprendizagem diante de objetos de desejo, de um texto, de um corpo, gênero e sexualidade são forjados e ao mesmo tempo forjam esses outros afetos. Lance a lance, em ato, dão-se combates, jogos de forças, negociações, piratarias, subversões, mal-entendidos (e bem-entendidos), (ab)usos, que fazem aparecer novos registros. Nesse sentido, travestis e pessoas trans, ao manipularem corpos, gênero e sexualidades, produzem fissuras nos discursos oficiais e em seus monumentos. Seus registros desenham (ou rascunham) outros possíveis. Esses acontecimentos têm muito a nos ensinar sobre as manipulações (e as manufaturas) dos corpos, do gênero e da sexualidade.

$\mathrm{O}$ que nos remete ainda mais uma vez a Certeau, quando fala sobre o (in)sucesso do colonizador.

Já faz muito tempo que se vêm estudando em outras sociedades as inversões discretas e, no entanto, fundamentais ali provocadas pelo consumo. Assim o espetacular sucesso da colonização espanhola no seio das etnias indígenas foi alterado pelo uso que dela se fazia: mesmo subjugados, ou até consentindo, 
muitas vezes esses indígenas usavam as leis, as práticas ou as representações que lhes eram impostas pela força ou pela sedução, para outros fins que não dos conquistadores. Faziam com elas outras coisas: subvertiam a partir de dentro - não rejeitando-as ou transformando-as (isto acontecia também), mas por cem maneiras de empregá-las a serviço de regras, costumes ou convicções estranhas à colonização da qual não podiam fugir. Eles metaforizavam a ordem dominante: faziam-na funcionar em outro registro. Permaneciam outros no interior do sistema que assimilava e que os assimilava exteriormente. Modificam-no sem deixá-lo. Procedimentos de consumo conservavam a sua diferença no próprio espaço organizado pelo ocupante. (CERTEAU, 1994, p. 94-95)

Na narrativa de Certeau, os indígenas desenvolvem a subversão como método e a dissimulação como estratégia. Isso não aconteceu apenas na América espanhola, mas também na portuguesa. E especialmente no Brasil - país com violento passado colonial e que nunca, nem de longe, se pareceu com a democracia racial imaginada por Gilberto Freyre - , o encontro de saberes indígenas, pretos, europeus produziram similares subversões e dissimulações. Hoje, tudo isso pode ser percebido nas pessoas travestis, em seus corpos e em como operam com marcadores de gênero e sexualidade.

À noite, esses corpos subversivos e dissimulados fazem festa. Dispersam-se por ruelas e becos, espaços impossíveis de serem percorridos por quem teme a escuridão da noite. Hibridizam-se com materiais da cultura midiática e, a partir deles, fabricam suas experiências e suas próprias imagens. Inventam, em gestos grupais, as culturas travestis. Como os indígenas em Certeau, fazem outra coisa do cisheterosistema de seus saberes. E, quando necessário, sabem ser pássaros noturnos e ofuscar as luzes da polícia de plantão.

A dissimulação das pessoas travestis e trans está em quase nunca corresponderem às nossas expectativas em relação a elas. Assim, elas nunca estão onde pensamos poder capturálas (ou onde as imagens esperam capturá-las). Imagens fugidias, borradas, quase indiscerníveis na noite. Para esses pirilampos, a vida é uma grande invenção.

Em gestos coletivos e grupais, essas pessoas aparecem, desaparecem, consomem e fabricam os corpos-gêneros-sexualidade conforme os desejos, as possibilidades e o senso de ocasião. Sabem falar muitas línguas (possuem um linguajar apenas delas) e sabem transitar por territórios inóspitos. E, como sabem também muitas linguagens, podem colocar a maquinaria do sistema-sexo-gênero em curto-circuito. 


\section{Verônica, Dandara e Suzy: imagem (des)contínuas da violência}

Até aqui, experimentando-nos, arriscando e fabricando territórios de escritas para nos haver com a cultura e a cultura visual, estabelecendo conversas com Certeau $(1994 ; 1995)$ para com ele problematizarmos uma produção expansionista e colonizadora sobre os corpos e os processos de subjetivação. Em nosso caso em específico, das pessoas travestis. Com o autor, buscamos afirmar uma certa arte de praticantes que inventam, em gestos grupais, corpos, gêneros, sexualidades, vidas e mundos.

Nessa escrita que se arrisca e marca processos de indignação, tomando as pessoas em dissidências - e tendo principalmente os gestos travestis como interlocutores, aos modos da criança que faz parar o culto para que nela prestemos atenção - , ampliamos a conversa com Judith Butler (2015) e, com ela, redobramos os sentidos de atenção aos nossos deslizes, traições e enquadramentos. Dizer isso é reconhecer, com Butler, que escrevemos com as marcas dos enquadramentos que nos subjetivam e nos informam sobre nossa humanidade (ou sua ausência).

Dizer isso, é também reconhecer as muitas imagens violentas, que nos usos de diferentes linguagens, circulam entre nós e nos ajudam a incorporar a indignação em nossas práticas políticas; uma indignação que é modo de vida e presença no mundo. Butler comenta a respeito de corpos em fotografias:

A fotografia não pode restituir a integridade ao corpo que registra. $\mathrm{O}$ rastro visual não equivale, certamente, à plena restituição da humanidade da vítima, por mais que isso seja obviamente desejável. A fotografia exibida e colocada em circulação, torna-se a condição pública mediante a qual nos indignamos e construímos nossas visões políticas para incorporar e articular a indignação. (BUTLER, 2015, p. 120)

Incorporamos e articulamos não apenas a indignação, mas também a exaustão causada pela quantidade de imagens (não apenas fotografias, mas charges, vídeos, filmes, documentários) que hoje circulam pelos mais diversos meios: redes sociais, televisão, telas de cinemas, pelas paredes que se recusam a permanecer uma tela em branco. Em nossas pálpebras quando dormimos ou quando "sonhamos acordados". E... nos movimentos sociais. Isso tudo é também a prática de tornar visível. E, sempre que algo opaco se coloca em nosso campo de visão, é quase certo que está produzindo visibilidade e, ao mesmo tempo, invisibilidade. A opção de que "tudo" pode estar visível ao mesmo tempo é uma ilusão criada por um mercado pautado pelo consumo. Sob essa lógica, consumir mais imagens equivaleria a ver mais. Tratase da quantidade de produtos consumidos, o que tem levado - e acreditamos não estarmos 
sozinhos nessa percepção — a uma quase overdose de informações. Podemos ouvir alguns reclamarem que, após tantas imagens que "precisam" ser consumidas, será que ainda precisamos das imagens travestis?

Mas nosso ponto não está na quantidade das imagens disponíveis, mas em sua qualidade. Por que tantas imagens opacas? Imagens que, ao mesmo tempo em que se dão a ver, também bloqueiam a visão? Nossa opção é por um regime de atenção que tente capturar imagens com menos opacidade e mais trans-parências.

Os pirilampos que aparecem na noite escura têm essa marca: parecem ao mesmo tempo estarem ali, mas então é como se desaparecessem, e então surgem novamente. Se as imagens ditas "hegemônicas" pudessem ser mais trans-parentes, seria possível ver a luz desses pirilampos. Mas é justamente a opacidade que constitui essas imagens como "hegemônicas". Por esse motivo, não procedem as críticas que acusam os corpos trans-parentes de desejarem “conquistar" um espaço "ocupado" por corpos hegemônicos (e aqui a linguagem bélica não é exatamente metáfora). Não se trata de substituir um corpo opaco por outro, mas de modificar a maneira como imagens são produzidas e consumidas. $\mathrm{Ou}$, ao menos, nesse regime de combates e jogos de forças e negociações e piratarias e subversões e mal-entendidos (e bem-entendidos) e (ab)usos etc., que as imagens possam (re)aprender a serem mais trans-parentes.

Como não estamos imunes às imagens (e aos sons) que nos atravessam quase sempre sem pedir autorização, presenciamos com indignação o extermínio de vidas que para as polícias do sistema sexo-gênero não são dignas de serem vividas, muito menos sentidas, choradas, enlutadas. Como se diz por aí, com a desconcertante opacidade das "obviedades": "quem mandou ser travesti?"”.

Nessas imagens que causam indignação, a opacidade esconde autores e obra, que, apesar disso, seguem a exigir um nome que não nos deixe esquecer. Porque precisamos vidas passíveis de luto, vidas mais trans-parentes, e, também, porque não podemos deixar de olhar para a carga insuportável de vulnerabilidade e de violência às quais algumas vidas estão expostas. "Quem mandou serem o que são?"

Pessoas travestis e seus sofrimentos, corpos exterminados e violentados comparecem amiúde nas telas dos computadores e de nossos celulares, e, também nas páginas policiais dos jornais e nos telejornais sensacionalistas que insistem em estar em telas que se espalham por toda parte, ainda que tentemos delas escapar. Seus corpos, sem vida e mutilados, murmuram um pedido de socorro já sem voz! Os olhos das travestis mortas violentamente tentam nos observar através dessas imagens. Nesses olhos, pode-se ver, sem filtros, toda nossa precariedade. São olhos que assustam pela opacidade, olhos que um dia exibiam vida e trans-parência. Revista Interinstitucional Artes de Educar. Rio de Janeiro, V. 7, N. 1 - pág. 254-271 janeiro-abril de 2021: "Pedagogias Vitais: Corpo, Desejo e Educação" DOI: 10.12957/riae.2021.54891 
Num piscar de olhos... somos apenas carne que grita e sangra até a morte, para logo depois desaparecer do enquadramento da câmera. Mesmo o gesto violento se mostra opaco, pois invisível enquanto ato (“ninguém sabe e ninguém viu”). Mas suas sádicas, cruéis e tristes consequências estão ali, visíveis como em uma autópsia, como objetos expostos na vitrine do sensacionalismo. As imagens de dor, já dizia Susan Sontag, causam indignação, mas, ao mesmo tempo, podem anestesiar. (SONTAG, 2003). “Outra travesti?” Isso não é mais novidade, não é notícia. E o mercado das imagens opacas pleiteia exatamente a novidade. Na voz de Elza Soares, "a carne mais barata do mercado é a carne preta". Mas a carne travesti e a carne trans-parente também estão em "liquidação".

Não é preciso esperar pela nova morte com seus enquadramentos opacos, nem pela imprensa escrita (que costuma se atrapalhar ao soletrar nomes trans-parentes) para que os acontecimentos violentos virem fato, causem nossa comoção e depois nos anestesiem e nos arremessem à nossa condição inumana.

A questão não é somente a fotografia, nem mesmo seus usos. Mas pela banalização dessas imagens, pela anestesia que recebemos dessas imagens opacas. Dos gemidos sem voz que pedem ao seu algoz que cesse o ato violento. Quase sempre, tais apelos não são sequer ouvidos, e menos ainda atendidos. Como o excesso de indignação pode também causar anestesia, corremos o risco de entrar no círculo vicioso prescrito por Sontag: com o excesso de acontecimentos, precisamos de cada vez imagens mais e mais "chocantes" para nos comovermos e mais uma vez nos indignarmos. E depois, novamente anestesiados, procuramos (como se viciados) por imagens ainda mais chocantes e assim sucessivamente. Nessa espécie de circuito fechado, indignação e exaustão parecem se encontrar como dia e noite: a indignação é tamanha que não pode ser suportada por muito tempo.

Mas os circuitos fechados de indignação, revolta (e exaustão e desânimo) funcionam como as imagens que chamamos de "opacas". Não precisamos reinventar as imagens, mas sim nossa relação com elas. Imagens e sons são hoje máquinas de quantificar corpos sem vida. $\mathrm{O}$ excesso de imagens e sons, os fluxos de imagens (a lógica dos feeds da internet) tendem a nos fazer esquecer que autor e obra reivindicam seus nomes!

Fazendo problema aos usos da fotografia e de sua circulação, Judith Butler (2015) pondera que,

Se a fotografia não apenas retrata, como constrói e amplia o acontecimento pode se dizer que a fotografia reitera e da continuidade ao acontecimento então, estritamente falando, ela não é posterior ao acontecimento, mas sim, se torna crucial para sua produção, sua legibilidade, sua ilegibilidade e seu próprio estatuto como realidade. Talvez a câmera promova uma crueldade Revista Interinstitucional Artes de Educar. Rio de Janeiro, V. 7, N. 1 - pág. 254-271 janeiro-abril de 2021: "Pedagogias Vitais: Corpo, Desejo e Educação" DOI: 10.12957/riae.2021.54891 
festiva: "Ah, que bom, a câmera está aqui: vamos começar com a tortura para que a fotografia possa captar e celebrar nosso ato!" Nesse caso, a fotografia já está em ação, incitando, enquadrando e orquestrando o ato, ao mesmo tempo que capta o ato no movimento de sua consumação. (BUTLER, 2015, p. 126)

Nos últimos anos, em nosso país, não se trata apenas de saber de atos violentos e da maximização da vulnerabilidade dos corpos contra-hegemônicos. Pelos computadores, celulares, telejornais, mídia impressa e, também por relatórios governamentais e nãogovernamentais, temos dados (subnotificados) de vidas ceifadas do direito de se expandirem e de florescerem. Pirilampos que desapareceram, às vezes sem alarde, em meio à grande noite que por vezes parece interminável. A fofoca miúda se faz acontecer em tempo real pelas telas e demais canais disponíveis. De nossas poltronas confortáveis, ficamos sabendo e sentimos o cheiro da morte, a faceta cruel do ódio e o desprezo pela vida e dignidade de Verônica Bolina, Dandara e Suzy.

Em 2015, Verônica Bolina, mulher trans negra, foi espancada e despida numa carceragem masculina e depois, diagnosticada como portadora de transtorno mental. Em janeiro de 2018, foi novamente detida, acusada de tentativa de homicídio e, até março de 2020, cumpria medida de segurança no Hospital de Custódia e Tratamento Psiquiátrico de Taubaté, no interior de São Paulo viii. Houve comoção nas redes sociais, além do surgimento da hashtag \#SomosTodosVeronica. Em solidariedade ao caso, uma arte viralizou:

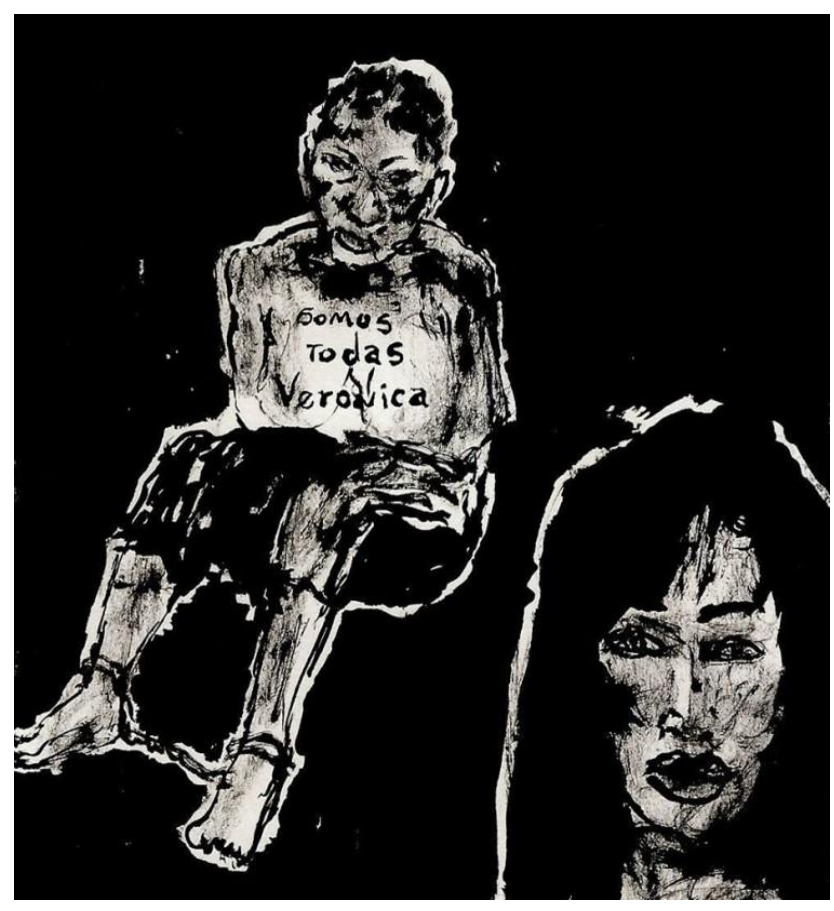

Figura 1: \#SomosTodasVeronica: arte que viralizou em solidariedade a Verônica Bolina ${ }^{\mathrm{ix}}$ 
Em outro caso, ocorrido a 15 de fevereiro de 2017, Dandara Kethlen (ou Dandara dos Santos para os registros cartorários), mulher trans, foi brutalmente espancada e depois executada a tiros em Fortaleza. Imagens do espancamento foram divulgadas nas redes sociais, causando comoção e promovendo a hashtag \#SomosTodosDandara. Pouco depois, outra hashtag surgiu, ligada à campanha \#PelaVidaDasPessoasTrans:

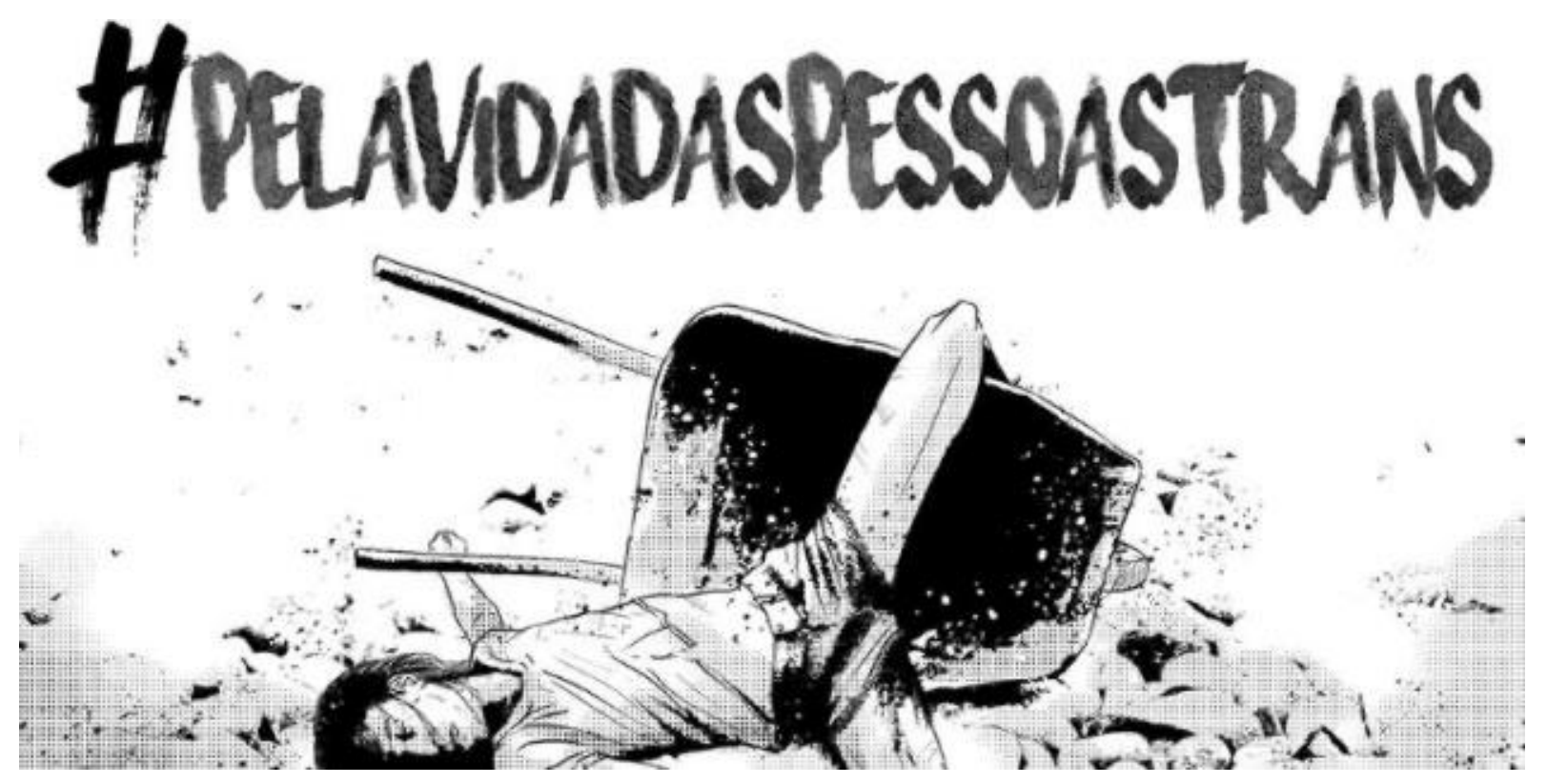

Figura 2: Imagem de Dandara utilizada na campanha \#PelaVidaDasPessoasTrans ${ }^{\mathrm{x}}$

Em abril de 2018, cinco homens foram condenados à prisão pelo crime de Dandara ${ }^{\mathrm{xi}}$.

Em março de 2020, durante uma reportagem do Fantástico, programa dominical da TV Globo, o médico Drauzio Varella conversou com a mulher trans Suzy Oliveira, detenta em Guarulhos, que lhe disse estar há oito anos sem receber visitas. A comoção causada pela matéria fez com que Suzy, em pouco menos de uma semana, recebesse "16 livros, duas bíblias, maquiagens, chocolate, envelopes, canetas e 234 cartas"xii. Porém, pouco depois, foi conhecida a causa da prisão de Suzy - condenada por estuprar e matar uma criança de nove anos - o que levou a uma polarização das redes midiáticas: alguns celebravam a solidariedade demonstrada para com Suzy, enquanto outros, condenavam o abraço que Suzy recebeu ${ }^{x i i i}$.

O abraço que Suzy recebeu de Dráuzio Varella também viralizou nas redes sociais: 


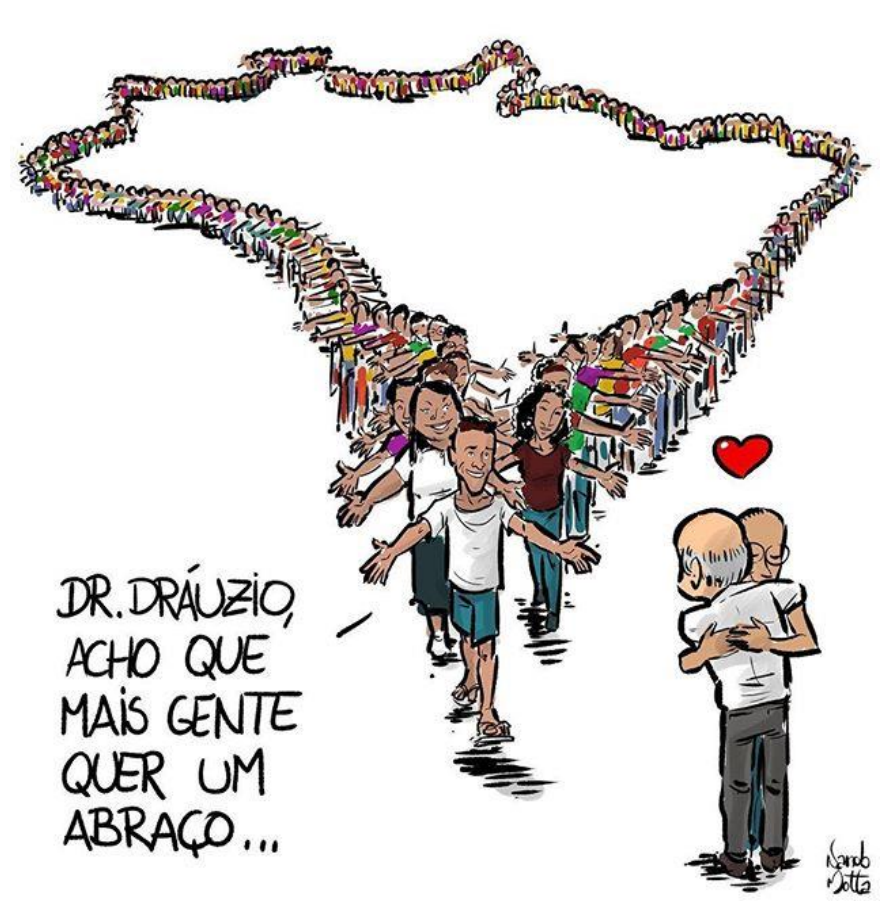

Figura 3: O cartum, de autoria do ilustrador Nando Motta, retrata o abraço de Dráuzio Varella em Suzy ${ }^{\mathrm{xiv}}$

Ao recapitular os casos de Verônica, Dandara e Suzy, não desejamos nos deter em um rio de sangue - que não para de aumentar em volume e velocidade. Ao invés disso, nos interessam os usos e os gestos que, nas reações a esses casos, conseguem formar coletividades e alianças. Nos interessam como esses acontecimentos produzem outras imagens trans-parentes, aquelas que não se dão a ver como óbvias, como o cheiro de flores que nascem do asfalto. Nos interessa, com esses acontecimentos, uma atenção aos nascimentos. Nos interessa, pensar os usos que fazemos de imagens e sons em políticas de aliança. Nos interessa atravessar a opacidade das imagens oficiais (e monumentais) com nossas trans-parências. Nos interessa, nesses jogos ópticos, descobrir e inventar novos reflexos e novas reflexões. Nos interessa visibilizar a luminosidade dos pirilampos em meio à noite escura.

As imagens e sons dos atos violentos não nos interessam apenas enquanto documento. Neste texto, buscamos nos permitir enquanto praticantes de espaços culturais, reconhecendo que, nessas práticas, é possível deslocar as marcas dos enquadramentos que buscam nos constituir como sujeitos de um certo tipo. Logo — assim como um enquadramento (na imagem) é algo que cria limites entre visibilidade e invisibilidade —, os modos de ver estão subjetivados pelos enquadramentos. 


\section{Os efeitos da corda bamba, desequilíbrios para (não) concluir}

Sobre vidas que não são as nossas e não nos pertencem, Certeau lembra que "é sempre bom recordar que não se deve tomar os outros por idiotas" (CERTEAU, 1994, p. 273), principalmente quando temos por desafio andarilhar no campo in aberto da mídia, dos processos culturais e suas pedagogias. É com isso que procuramos nos haver neste artigo.

Em nosso percurso - através de recortes de outras paragens culturais com aparecem nas mídias sociais -, não tentamos uma definição última para o conceito de cultura, seja no singular, seja no plural. Preferimos afirmá-la, provisoriamente, como uma "revolução de há pouco", produto de enquadramentos e fragmentos de narrativas travestis a maquinar outros discursos. Corpos que dependem da arte da narrativa (e da narrativa dessa arte) para se manterem vivos. Narrativas travesti, arte travesti, modos de fazer - gestos, gostos, experiências práticas com os corpos, gêneros e sexualidades, essa busca por (des)aprender ao mesmo tempo em que se equilibra sobre a corda bamba.

Com elas, se dispostos estivermos, aprenderemos que a arte travesti é um

Dançar sobre a corda é de momento em momento manter um equilíbrio, recriando-o a cada passo graças a novas intervenções; significa conservar uma relação nunca de todo adquirida e que por uma incessante invenção ser renova com a aparência de conservá-la. A arte de fazer fica assim admiravelmente definida, ainda mais que efetivamente o próprio fabricante faz parte do equilíbrio que ele modifica sem comprometê-lo. Por essa capacidade de fazer um conjunto novo a partir de um acordo preexistente e de manter uma relação formal malgrado a variação dos elementos, tem muita afinidade com a produção artística. Seria uma inventividade incessante de um gosto na experiência prática. (CERTEAU, 1994, p. 146)

Nesse caminho, aberto a golpes na (e com a) escrita, pensada aqui também como artefato cultural, um artefato nunca "neutro" — de onde nosso empenho por um estilo do desvio, em um texto que não imponha discursos aos corpos trans-parentes, mas que sirva como um anteparo por onde a luz possa atravessar e as imagens resultantes sejam mistura.

Que por entre as palavras de nossa experiência textual possamos estar atentos para os modos (precários?) como algumas vidas (precárias) são expostas. Uma cultura na dimensão da precariedade em que

A precariedade tem de ser compreendida não apenas como um aspecto desta ou daquela vida, mas como uma condição generalizada cuja generalidade só pode ser negada negando-se a precariedade enquanto tal. E a obrigação de pensar a precariedade em termos de igualdade surge precisamente da irrefutável capacidade de generalização dessa condição. Partindo desse 
pressuposto, contesta-se a alocação diferencial da precariedade e da condição de ser lamentado. Além disso, a própria ideia de precariedade implica uma dependência de redes e de condições sociais, o que sugere que aqui não se trata da vida como tal, mas sempre e apenas das condições de vida, da vida como algo que exige determinadas condições par se tornar uma vida vivível e, sobretudo, para torna-se uma vida passível de luto. (...). Mas uma obrigação, com efeito surge de fato de que somos, por assim dizer, seres sociais desde o começo, dependentes do que está fora de nós, dos outros, de instituições e de ambientes sustentados e sustentáveis, razão pela qual somos nesse sentido, precários. (BUTLER, 2015, p. 42-43)

Nosso texto volta-se a si mesmo (revolta-se contra si mesmo) como as imagens que anteriormente definimos estar "em curto-circuito". Ao interrogar os modos como as travestis se configuraram nos enquadramentos dos artefatos culturais, tentamos abrir um debate que possa articular os fragmentos para concluir com uma imagem sempre e necessariamente incompleta

Os equilíbrios são sempre fugazes, e a indignação causada pelas imagens tem uma data de validade cada vez mais curta - necessidade midiática de abrir caminho para uma nova imagem de indignação e assim sucessivamente. A indignação sozinha, porém, não basta para criar (a imagem de) um povo. A travestilidade e seus gestos grupais, seus atos e acontecimentos, suas produções socioculturais tornam-se visíveis seja em seus próprios discursos, seja invadindo (subvertendo e dissimulando) os discursos hegemônicos. As performances dos corpos trans-parentes estão inscritas nos momentos históricos de suas elaborações e de suas condições de existência.

E, ainda assim, e apesar com tais datas de validade cada vez menores, não podemos esquecer Verônica, Dandara e Suzy. Nossa obrigação ética é a visibilidade das travestilidades na cultura - em fotografias, filmes, documentários, teatros, telejornalismo, livros, desenhos animados etc., questão que se tornou, não sem tempo, central para as empresas de mídia, os diversos ativismos e (ainda timidamente) as políticas governamentais (macropolíticas) produzidas no Brasil.

Uma imagem capturada por uma câmera, depois processada, modificada e difundida, "é uma espécie de promessa de que o acontecimento vai continuar; na verdade, ela é exatamente essa continuação" (BUTLER, 2015, p. 127). Tornar-se visível é apenas mais uma dimensão de que somos dignos de luto, bem como de estarmos inseridos no contexto de uma consciência política relevante.

Recorrendo aos trabalhos de Sontag sobre fotografia, Butler deixa um alerta:

... não podemos compreender o campo da representabilidade simplesmente examinando seus conteúdos explícitos, uma vez que ele é constituído 
fundamentalmente pelo que é deixado de fora, mantido fora do enquadramento dentro do qual as representações aparecem. Podemos pensar no enquadramento, então como algo ativo, que tanto descarta como mostra, e que faz duas coisas ao mesmo tempo, em silêncio, sem nenhum sinal visível da operação. O que surge nessas condições é um espectador que supõe estar em uma relação visual imediata e incontestável com a realidade. (....) Existem maneiras de enquadrar que mostram o humano em sua fragilidade e precariedade, que nos permitem defender o valor da dignidade da vida humana, reagir com indignação quando vidas são degradas ou dilaceradas sem que se leve em conta seu valor enquanto vidas. E há enquadramentos que impedem a capacidade de resposta, nos quais essa atividade de impedimento é realizada pelo próprio enquadramento efetiva e repetidamente - sua própria ação negativa, por assim dizer, sobre o que não será explicitamente representado. A existência de enquadramentos alternativos que permitem outros tipos de conteúdo talvez comunicasse um sofrimento que poderia levar a uma alteração de nossa avaliação política das guerras em curso. (...) $\mathrm{O}$ enquadramento atua para estabelecer uma relação entre o fotografo, a câmera e a cena. (BUTLER, 2015, p. 112, 118 e 122)

Quais dos enquadramentos, entre os citados por Butler, estão sendo usados em relação às travestilidades? Que opacidades e que transparências são operacionalizadas na (con)formação dos pirilampos e de suas imagens midiáticas? Não é mais possível negar que as vidas trans-parentes estão aqui, ao nosso redor, por toda a parte. Para aqueles que tiverem olhos para ver.

\section{REFERÊNCIAS}

AMARAL, M.S. et al. Do travestismo às travestilidades: uma revisão do discurso acadêmico no Brasil entre 2001-2010. Psicologia \& Sociedade, vol. 26, nº 2, 2014, p. 301311.

BUTLER, J. Corpos em aliança e a política das ruas: notas para uma política performativa de assembleia. tradução: Fernanda Siqueira Miguens. Rio de Janeiro: Civilização Brasileira, 2018.

BUTLER, J. Quadros de guerra: quando a vida é passível de luto. tradução: Sergio Lamarão; Arnaldo Marques da Cunha. Rio de Janeiro: Civilização Brasileira, 2015.

CERTEAU, M. A invenção do cotidiano, vol. 1: artes de fazer. tradução: Ephraim Ferreira Neto. Petrópolis: Vozes, 1994.

CERTEAU, M. A cultura no plural. tradução: Eni Abreu Dobránsky. Campinas: Papirus, 1995.

SONTAG, S. Diante da dor dos outros. tradução: Rubens Figueiredo. São Paulo: Companhia das Letras, 2003. 
${ }^{\text {i }}$ Pós-Doutor em Psicologia (UFF), Doutor em Educação (UFES). Professor do do Centro de Educação e do Programa de Pós-Graduação em Psicologia Institucional da Universidade Federal do Espírito Santo. Brasil. ORCID Id: https://orcid.org/0000-0002-5998-4978

ii Doutor em Meios e Processos Audiovisuais pela Escola de Comunicações e Artes e Mestre em Comunicação Impressa e Audiovisual pela Universidade de São Paulo. UFES/professor no curso de Cinema e Audiovisual e no Programa de Pós-Graduação em Psicologia Institucional. Brasil. ORCID Id: https://orcid.org/0000-0002$\underline{1767-3610}$

iii Graduada em Psicologia pela Universidade Federal do Espírito Santo (1997). Mestre em Psicologia Social, pela Universidade do Estado do Rio de Janeiro (2001). Doutora em Educação pelo Programa de Pós-Graduação em Educação (2009) na Universidade Federal do Espírito Santo / UFES. Professora do Curso de Psicologia e do Programa de pós-graduação em Psicologia Institucional, UFES. Tem experiência na área de Psicologia, com ênfase nas propostas grupalistas e processos educacionais e formativos. Brasil. ORCID Id: https://orcid.org/0000-0003-2292-7037

iv Doutor em Educação (UFES). Professor do Departamento de Saúde Coletiva e do Programa de Pós-Graduação em Saúde Coletiva da UFMT. Universidade Federal de Mato Grosso/ Instituto de Saúde Coletiva. Brasil.

ORCID Id: https://orcid.org/0000-0003-2696-5786

v “põe a cara no sol, mona!”. Disponível em: 〈https://www.youtube.com/watch?v=kvIkULPtIOk〉. Acesso em: 21 mar. 2020.

vi “Conheça Natasha, a criadora do bordão 'Põe a cara no sol, mana', novo sucesso na web”. Disponível em: $<$ https://extra.globo.com/noticias/viral/conheca-natasha-criadora-do-bordao-poe-cara-no-sol-mana-novosucesso-na-web-15175686.html>. Acesso em: 21 mar. 2020.

vii “natashamartory”. Disponível em: < https://www.instagram.com/natashamartory/>. Acesso em: 21 mar. 2020. viii "Verônica Bolina: como um caso de saúde mental virou caso de polícia”. Disponível em:

<https://ponte.org/veronica-bolina-como-um-caso-de-saude-mental-virou-caso-de-policia/>. Acesso em: 21 mar. 2020.

${ }^{\text {ix }}$ QUINTANILHA, Renan. “Presa, negra e travesti: devemos ser todas Verônica”. Disponível em: <https://ponte.org/presa-negra-e-travesti-devemos-ser-todas-veronica/>. Acesso: 21 mar. 2020.

x “CDHM cobra providências de autoridades sobre assassinato da travesti Dandara”. Disponível em: <https://www2.camara.leg.br/atividade-legislativa/comissoes/comissoes-permanentes/cdhm/noticias/cdhmcobra-providencias-de-autoridades-sobre-assassinato-da-travesti-dandara/>. Acesso em: 20 jun. 2020.

${ }^{\mathrm{xi}}$ LAVOR, Thays. "Cinco são condenados à prisão por morte da travesti Dandara”. Disponível em: <https://www1.folha.uol.com.br/cotidiano/2018/04/cinco-sao-condenados-a-mais-de-14-anos-de-prisao-pormatar-travesti-no-ceara.shtml>. Acesso em: 20 jun. 2020.

xii “Após ter seu caso revelado por Drauzio Varella, presa trans já recebeu 234 cartas".

$<$ https://www1.folha.uol.com.br/cotidiano/2020/03/apos-ter-seu-caso-revelado-por-drauzio-varella-presa-transja-recebeu-234-cartas.shtml>. Acesso em: 20 jun. 2020.

xiii “Após revelação de crime, detenta trans, Drauzio Varella e Globo se manifestam”. Disponível em: <https://emais.estadao.com.br/noticias/comportamento,detenta-trans-drauzio-verella-globo-semanifestam,70003226135>. Acesso em: 20 jun. 2020.

xiv “Dr. Dráuzio, acho que mais gente quer um abraço...”. Disponível em:

<https://www.facebook.com/radiopontal104.3/photos/a.983216498361076/3306827199333316>. Acesso em: 20 jun. 2020. 